\title{
Aspirin inhibits RANKL-induced osteoclast differentiation in dendritic cells by suppressing NF-KB and NFATc1 activation
}

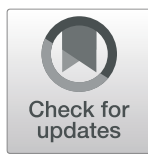

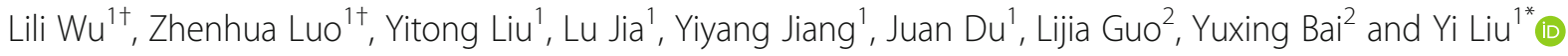

\begin{abstract}
Background: Aspirin has been demonstrated to promote osteoblast-mediated bone formation and inhibit osteoclast (OC)-mediated bone resorption. However, it remains unclear whether aspirin influences other immune cells during bone resorption. Dendritic cells (DCs), the most potent antigen-presenting cells, can also transdifferentiate into active OCs in the presence of receptor activator of nuclear factor-KB ligand (RANKL) and macrophage colony-stimulating factor (M-CSF). The effects of aspirin on DC-derived OCs (DDOCs) were investigated in the current study.

Methods: Flow cytometry and mixed lymphocyte reaction (MLR) assays were used for DC identification. The proliferative capacity of DCs was determined by BrdU assays. Apoptosis was examined by flow cytometry. The osteoclastic potential of DCs was tested using tartrate-resistant acid phosphatase (TRAP) staining, western blotting, and reverse transcription polymerase chain reaction (RT-PCR). Western blotting was also used to examine signaling pathways. A mandibular bone defect model was established to assess the effect of aspirin on bone resorption.
\end{abstract}

Results: Aspirin had no influence on the surface phenotype, proliferation, or apoptosis of DCs, though aspirin significantly inhibited osteoclast differentiation in RANKL-stimulated DCs. DC osteoclast differentiation was modulated by aspirin via the nuclear factor kappa B (NF-kB)/nuclear factor of activated T cell, cytoplasmic 1 (NFATC1) signaling pathway. Aspirin treatment also had favorable therapeutic effects on bone regeneration in the bone defect model, and the number of osteoclasts was decreased.

Conclusions: Aspirin inhibited RANKL-induced OC differentiation in DCs via the NF-KB pathway, downregulating expression of NFATC1. Aspirin treatment promoted bone regeneration by inhibiting DDOC activation in the early stages of inflammation in a rat mandibular bone defect model.

Keywords: Aspirin, Dendritic cells, Osteoclasts, Receptor activator for nuclear factor-KB ligand (RANKL)

\section{Background}

Bone homeostasis is maintained through the balance between the activity of osteoclasts (OCs) and that of osteoblasts. However, in some inflammatory diseases, such as osteoporosis and periodontitis, bone resorption exceeds bone formation, creating an imbalance caused by abnormal activation of OCs [1].

\footnotetext{
* Correspondence: lililiuyi@163.com

†Lili Wu and Zhenhua Luo contributed equally to this work.

'Laboratory of Tissue Regeneration and Immunology and Department of Periodontics, Beijing Key Laboratory of Tooth Regeneration and Function Reconstruction, School of Stomatology, Capital Medical University, Tian Tan Xi Li No.4, Beijing 100050, People's Republic of China

Full list of author information is available at the end of the article
}

OCs, unique cells capable of dissolving bone matrix, are derived from the monocyte/macrophage lineage of hematopoietic precursors. OC differentiation and activation is regulated by two critical cytokines: macrophage colony-stimulating factor (M-CSF) and receptor activator of nuclear factor $k B$ ligand (RANKL) [2]. During differentiation, the fusion of mononuclear precursors is indispensable for the formation of mature multinucleated OCs, which play an essential role in resorbing bone [3].

In addition to the major involvement of OCs in bone homeostasis, the involvement of other immune cells in bone resorption has been shown in several studies. Dendritic cells (DCs), the major antigen-presenting cells, 
also share several features with OCs; they are derived from the same myeloid precursor, and the functions of both cell types are closely dependent upon RANKL [4]. Interestingly, there is increasing evidence that immature DCs (imDCs) have osteoclastogenic potential in some inflammatory pathological conditions because imDCs can transdifferentiate into active OCs after stimulation with RANKL and M-CSF [5, 6]. These findings clearly highlight a potential link between DCs and OCs.

Because of the major involvement of OCs in bone homeostasis, a feasible strategy is to inhibit osteoclastogenesis and/or decrease bone resorption activity in active OCs to prevent or treat bone resorption-related disorders. Aspirin is a classic nonsteroidal anti-inflammatory drug (NSAID) that is well known for its antipyretic, analgesic, and anti-inflammatory effects. Aspirin irreversibly inhibits cyclooxygenase-1(COX-1) and cyclooxygenase-2 (COX-2) activities via covalent modification [7]. Moreover, multiple animal and clinical studies have reported that COX-2 inhibition negatively affects bone healing [811], though a small minority of these studies have demonstrated no lasting negative effects [11-13]. Recent studies have shown that aspirin can regulate the bone balance in ovariectomy-induced osteoporosis [7]. Furthermore, aspirin was found to inhibit RANKL-induced osteoclastogenesis in RAW264.7 cells [14]. However, the effects of aspirin on bone healing remain highly debated. The main factors that may underlie the discrepancies between studies are the mode of administration, the variability of the drug dose, the dosing duration, and the type of bone defect model [11]. According to our previous studies, aspirin is able to promote bone marrow mesenchymal stem cell (BMSC)-based skull bone regeneration in mini-pigs after release in a local, sustained, and controlled manner [15]. In the present study, we examined whether aspirin regulates dendritic cell-derived osteoclast (DDOC) formation and activation.

\section{Materials and methods \\ Animals}

C57BL/6J mice (male, aged 8-10 weeks) and rats were sourced from the Institute of Vital River (Beijing, China). This study was performed according to institutionally set guidelines for animal research.

\section{Isolation and culture of $\mathrm{CD} 11 \mathrm{c}^{+} \mathrm{DCs}$}

Murine DCs were generated from bone marrow precursors. Bone marrow single-cell suspensions were generated from tibias and femurs and filtered through a $70-\mu \mathrm{m}$ strainer (BD Bioscience, $\mathrm{CN}$ ). The cells were then incubated with Red Blood Cell Lysis Buffer (APPLYGEN, China) and washed. The cells were then seeded in six-well plates $\left(10^{6}\right.$ cells $\left./ \mathrm{ml}\right)$ in RPMI-1640 medium (Gibco, USA) containing 10\% heat-inactivated fetal bovine serum (FBS),
$100 \mu \mathrm{g} / \mathrm{ml}$ streptomycin, $100 \mathrm{U} / \mathrm{ml}$ penicillin, and $2 \mathrm{mM} \mathrm{L-}$ glutamine and supplemented with $25 \mathrm{ng} / \mathrm{mL}$ recombinant mouse GM-CSF (rmGM-CSF; R\&D Systems, USA). The cells were induced for 3-7 days, and then imDCs were induced to mature by the addition of TNF-alpha (PeproTech, USA, $20 \mathrm{ng} / \mathrm{ml}$ ) for $24 \mathrm{~h}$ before harvesting on the 7th day.

\section{Surface markers of DCs after aspirin treatment}

DCs cultured with or without aspirin were prepared for surface marker expression analysis by FACS staining. Cells were incubated on ice for 15-30 min with specific monoclonal antibodies (mAbs): FITC-labeled anti-CD11c, PerCP/Cy5.5-labeled anti-MHC class II, PE-labeled antiCD80, and APC-labeled anti-CD86 (BD Biosciences, USA). After staining, the labeled cells were analyzed with a $\mathrm{BD}$ FACSCanto II flow cytometer (BD Biosciences).

\section{Isolation and culture of $\mathrm{CD}^{+} \mathrm{T}$ cells}

A mixed lymphocyte reaction (MLR) assay was employed to determine the functional activity of DCs; T lymphocytes were used as responder cells. $\mathrm{CD} 4^{+} \mathrm{T}$ cells were isolated from splenocyte suspensions and sorted by MIDI magnetic cell sorting (MACS; Miltenyi Biotec, Germany). Naive $\mathrm{CD}^{+} \mathrm{T}$ cells were incubated in $\mathrm{T}$ cell culture medium (RPMI-1640 medium containing 10\% FBS, 2 mmol/L-glutamine, $100 \mu \mathrm{g} / \mathrm{ml}$ streptomycin, $100 \mathrm{U} / \mathrm{ml}$ penicillin, and $20 \mathrm{~mol} / \mathrm{L}$ HEPES; Invitrogen, USA). The naive $\mathrm{CD}^{+} \mathrm{T}$ cells were activated using soluble anti-mouse CD28 $(2.5 \mu \mathrm{g} / \mathrm{ml})$ and plate-bound anti-mouse CD3 $(5 \mu \mathrm{g} / \mathrm{ml})$ antibodies.

\section{MLR assay}

To analyze $\mathrm{T}$ cell proliferation, cells $\left(1 \times 10^{6}\right)$ were labeled with $5 \mathrm{mM}$ carboxyfluorescein succinimidyl ester (CFSE; Life Technologies, USA) for $15 \mathrm{~min}$ in PBS (1\% BSA). The cells were seeded in round-bottom 96-well plates to ensure effective $\mathrm{DC} / \mathrm{T}$ cell interaction, after which DCs were added in gradient doses to activate the $\mathrm{T}$ cells $\left(1 \times 10^{5}\right.$ cells per well). The cells were cultured for $72 \mathrm{~h}$, and the proliferation of the CD4+ T cells in response to priming by the DCs was assessed by FACS. Data were analyzed using ModFit LT.

\section{BrdU assay for cell proliferation}

ImDC proliferation was evaluated with BrdU Cell Proliferation Assay Kit (BioVision, USA). DCs $\left(5.0 \times 10^{3}\right.$ cells/ well) were seeded in triplicate in a 96-well flat-bottom plate (Costar, USA) and incubated in $200 \mu \mathrm{l}$ of standard culture medium with or without aspirin for $24 \mathrm{~h}$. The cultures were then incubated with a BrdU solution for $4 \mathrm{~h}$. Absorbance at $450 \mathrm{~nm}$ was measured using an enzymelinked immunosorbent assay (ELISA) reader (ELx800; 
Table 1 Primers used for RT-PCR

\begin{tabular}{ll}
\hline Gene symbol & Sequence $\left(5^{\prime}->3^{\prime}\right.$ ) \\
\hline Mouse TRAP & (F)AGCAGCCAAGGAGGACTAC \\
Mouse CTSK & (R)CATAGCCCACACCGTTCTC \\
(F)AGCTTCCCCAAGATGTGAT \\
(R)AGCACCAACGAGAGGAGAA \\
(F)CTCCTTGTCGATTGCTGCT \\
(R)TCACCCTCTGGCAGCTAAG \\
(F) TGTAGACCATGTAGTTGAGGTCA \\
(R) AGGTCGGTGGAACGGATTG
\end{tabular}

$F$ forward, $R$ reverse

Bio-Tek Instruments Inc., USA), with the optical density (OD) value at $450 \mathrm{~nm}$ representing proliferating cells.

\section{Apoptosis assay}

To detect apoptotic cells in the presence or absence of aspirin, apoptosis was assessed using Annexin V Apoptosis Detection Kit FITC (eBioscience, USA).

\section{OC differentiation and the tartrate-resistant acid phosphate (TRAP) assay}

imDCs were further differentiated with $\alpha$-minimum essential medium ( $\alpha$-MEM; Gibco, USA) containing 100 $\mathrm{ng} / \mathrm{ml}$ RANKL and $25 \mathrm{ng} / \mathrm{ml} \mathrm{M-CSF}$ to obtain OCs.
A leukocyte acid phosphatase kit (Sigma-Aldrich) was utilized to examine the TRAP activity of adherent OC cultures. If TRAP-positive cells had three or more nuclei, they were considered OCs. TRAP-positive cells were analyzed by cell counting in at least five random fields under a light microscope (OLYMPUS, Japan).

Reverse transcription polymerase chain reaction (RT-PCR) imDCs $\left(10^{6}\right.$ cells $\left./ \mathrm{ml}\right)$ were plated in a six-well plate with various concentrations of aspirin and cultured for 5-7 days in culture medium. Total RNA was isolated from the cultured cells with TRIzol reagent (Invitrogen, USA) and reverse transcribed into cDNA using oligo (dT) according to the manufacturer's protocol (Invitrogen, USA). Real-time PCR was performed using iCycler iQ Multi-Color Real-time PCR Detection System and a QuantiTect SYBR Green PCR kit (Qiagen, Germany). The specific primer sequences used are listed in Table 1 .

\section{Western blot analysis}

imDCs were plated in six-well plates and treated with aspirin for $24 \mathrm{~h}$ prior to treatment with RANKL and MCSF. The cells were lysed in RIPA Lysis Buffer (Beyotime, China). Nuclear proteins were extracted using an EpiQuik Nuclear Extraction kit (EpiGentek, USA). Protein extracts were separated by $10 \%$ SDS polyacrylamide

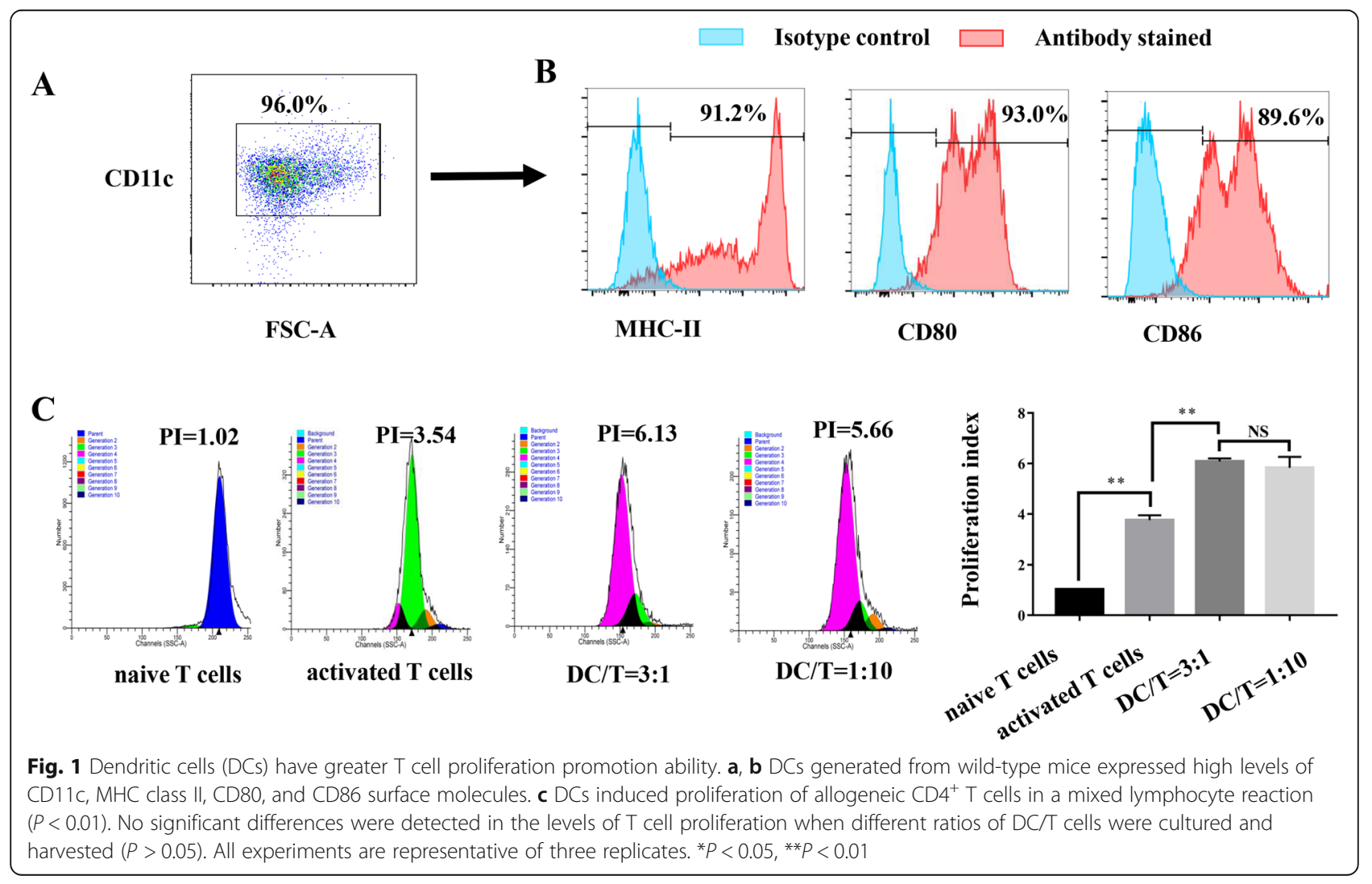


gel electrophoresis (Applygen, China), and subsequent processes were performed following a standard protocol.

\section{Mandibular bone defect model}

We established a mandibular bone defect in rats ranging from the incisors to the molars, $5 \mathrm{~mm}$ long, $2 \mathrm{~mm}$ wide, and $1 \mathrm{~mm}$ high, under general anesthesia (10\% pentobarbital, $40 \mathrm{mg} / \mathrm{kg}$ ). After surgery, all rats were randomly divided into aspirin and control groups. We mixed hydrogel $(500 \mu \mathrm{l}$, BeaverBio, China) and hydroxyapatite/ tricalcium phosphate (HA/TCP) $(20 \mathrm{mg})$ with or without $150 \mu \mathrm{g} / \mathrm{ml}$ aspirin and filled the mandibular bone defect with this mixture, followed by suturing the incisions intermittently with $0-4$ absorbable sutures (Fig. 5a). The rats were sacrificed on days 3 and 14 and at 2 months.

\section{Histological evaluations of the bone defect}

After rats were sacrificed, the defective area in the rat mandibular bone was observed by stereomicroscopy. After the mandibular bones were fixed in $4 \%$ paraformaldehyde (PFA), they were decalcified with buffered $10 \%$ EDTA (pH 8.0) and embedded in paraffin. The tissues were sectioned at $5 \mu \mathrm{m}$ and stained with TRAP and hematoxylin and eosin (H\&E).

\section{Immunohistochemical staining}

We euthanized rats after surgery to perform immunohistochemical examinations. Paraffin-embedded sections acquired as described above were dewaxed in xylene and dehydrated in alcohol. To reduce nonspecific staining, all sections were incubated with 3\% hydrogen peroxide and then blocked with $10 \%$ serum. Next, the samples were incubated with a mouse anti-rat $\mathrm{CD} 11 \mathrm{c}$ antibody (1200, Abcam, UK) and treated with biotinylated secondary antibodies. After the samples were developed by $\mathrm{DAB}$ staining and counterstained, observations were performed with a confocal microscope (OLYMPUS, Japan). Positively stained cells were counted in at least five random fields and quantified using Image-Pro Plus 6.0.

\section{Statistical analysis}

GraphPad Prism7 was used for statistical analysis. Unless otherwise noted, statistical significance comparisons of two groups were performed by Student's $t$ test, and one-way ANOVA was applied for comparisons among multiple groups. For samples with heteroscedasticity, KruskalWallis and Mann-Whitney $U$ tests were used to evaluate differences.
A

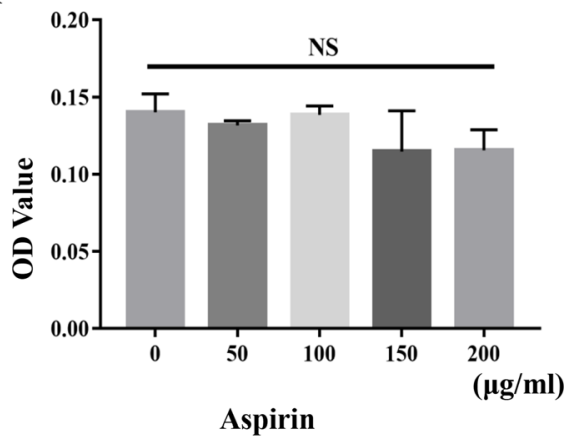

C

DCs

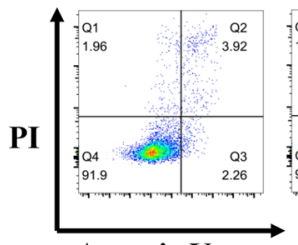

Annexin V

$$
\begin{aligned}
& \text { DCs + aspi } \\
& (50 \mu \mathrm{g} / \mathrm{ml})
\end{aligned}
$$
$(100 \mu \mathrm{g} / \mathrm{ml})$

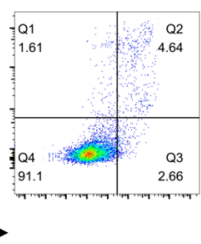

B

imDCs

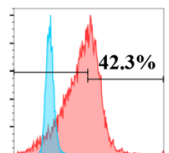

mDCs
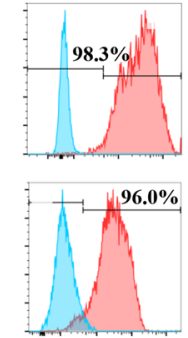

mDCs+aspirin

DCs + aspirin

DCs + aspirin

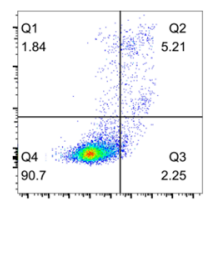
$(150 \mu \mathrm{g} / \mathrm{ml})$

DCs + aspirin $(200 \mu \mathrm{g} / \mathrm{ml})$

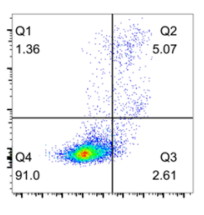

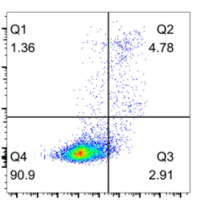
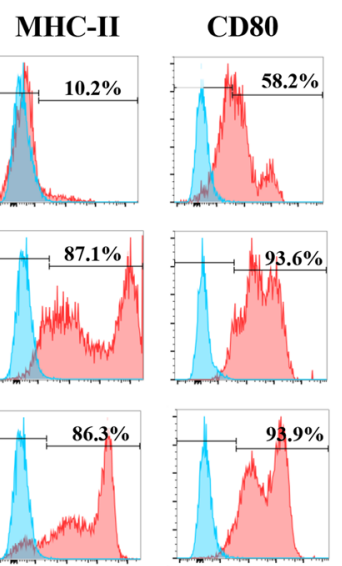

CD86
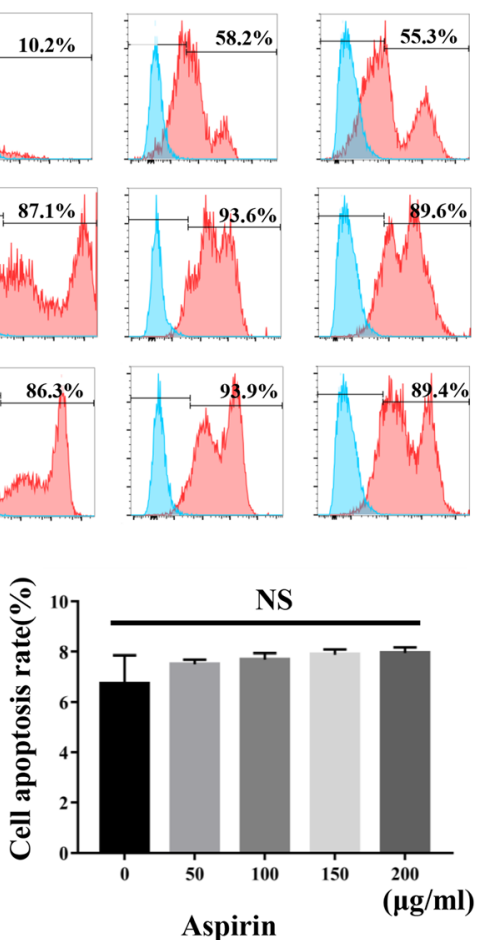

Fig. 2 Aspirin has no influence on DC apoptosis, proliferation, or immunophenotype. a Aspirin was not found to exert different effects on cell proliferation at the concentrations tested $(P>0.05)$. $\mathbf{b}$ Immature DCs (imDCs) expressed low levels of CD11c, MHC class II, CD80, and CD86 surface molecules; mature DCs highly expressed these surface molecules. Expression of surface markers on DCs with or without aspirin treatment showed no obvious differences. $\mathbf{c}$ The addition of aspirin had no influence on DC apoptosis $(P>0.05)$. All experiments are representative of three replicates. ${ }^{*} P<0.05$, ${ }^{* *} P<0.01$ 


\section{Results}

Isolation and characterization of DCs

imDCs can be stimulated to mature by exposure to cytokines. TNF- $\alpha$ induced maturation of DCs, which was characterized by significantly increased expression of CD11c, the costimulatory molecules CD80 and CD86, and the antigen-presenting molecule MHC class II (Fig. 1a, b).

The DCs were then tested for their ability to promote the proliferation of allogeneic $\mathrm{CD} 4^{+} \mathrm{T}$ cells in an MLR assay. CFSE-labeled naive $\mathrm{CD} 4^{+} \mathrm{T}$ cells were cocultured with different numbers of DCs. The cells were harvested on day 3 , and the number of proliferating cells had increased (Fig. 1c; $P<0.01$ ).

\section{Effect of aspirin on imDC proliferation and apoptosis}

The effects of aspirin on imDCs were evaluated by culturing imDCs with aspirin at different concentrations, followed by assessment of the rates of cell proliferation and apoptosis. Aspirin did not have different effects on cell proliferation at the concentrations tested (Fig. 2a; $P>$ 0.05 ). Additionally, aspirin did not dramatically induce apoptosis in imDCs (Fig. 2c; $P>0.05$ ).

\section{Aspirin was inefficient at modulating the DC surface phenotype}

Cells were treated with aspirin overnight before maturation with TNF- $\alpha$. The aspirin-treated DCs displayed a surface expression pattern similar to that of untreated cells, as the levels of CD11c, CD80, CD86, and MHC-II expression on the cell surface were higher than those on the imDC cell surface (Fig. 2b).

\section{Aspirin inhibited OC differentiation in RANKL-stimulated imDCs}

We then examined whether aspirin treatment can inhibit the osteoclastic potential of imDCs. imDCs were induced by RANKL and M-CSF as well as aspirin $(0,50,100,150$, or $200 \mu \mathrm{g} / \mathrm{ml}$ ) and then stained after 7 days of culture

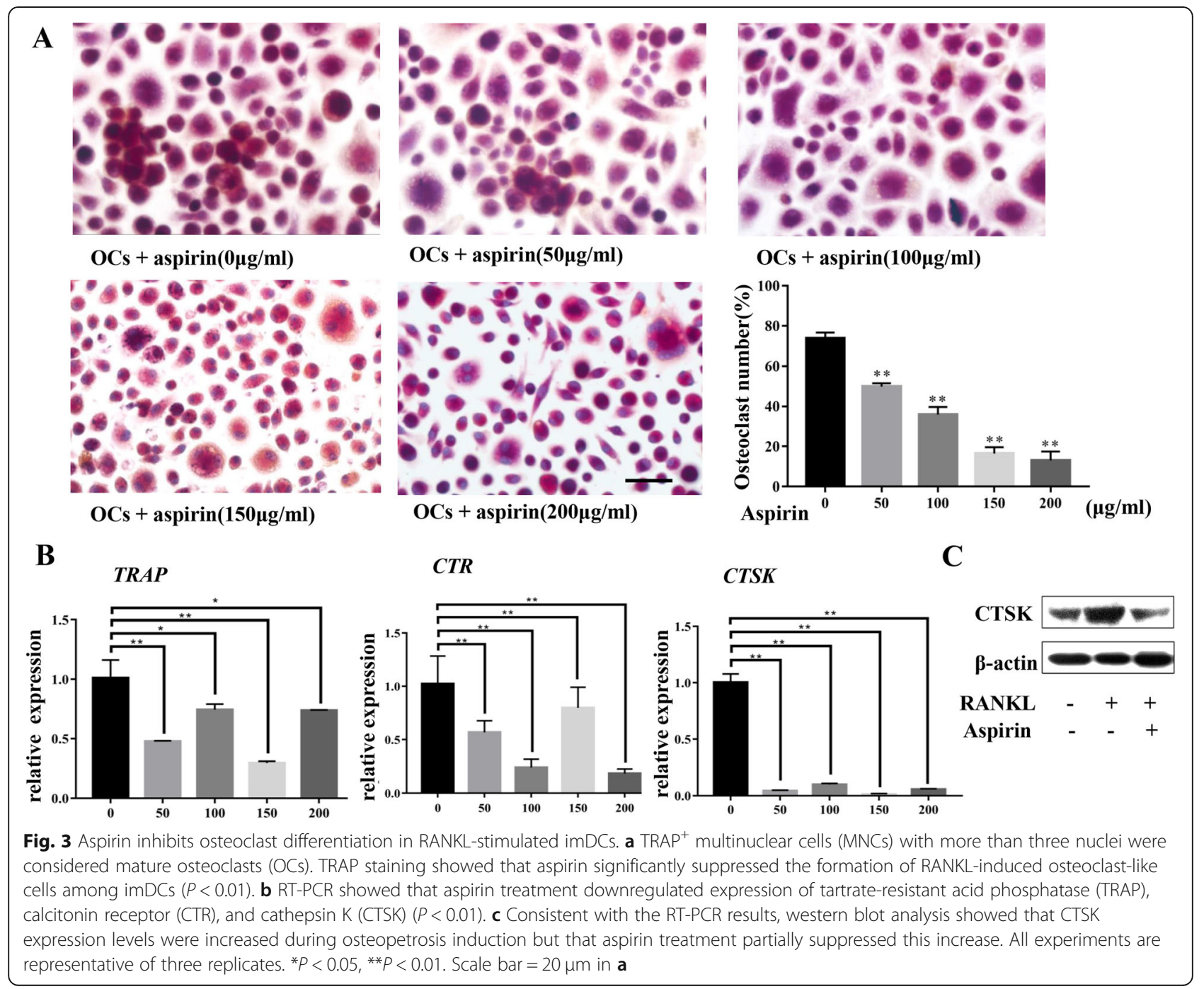


(Fig. 3a; $P<0.01$ ). The results demonstrated that aspirin suppressed the formation of OC-like cells following stimulation with RANKL, which was verified by the downregulation of OC-specific marker gene (cathepsin K (CTSK), TRAP, and calcitonin receptor (CTR)) expression in imDCs cultured under OC-inducing conditions with aspirin for 5 days (Fig. 3b; $P<0.01$ ). As the reduced gene expression was most stable and significant in the $150 \mu \mathrm{g} /$ $\mathrm{ml}$ aspirin group, we used this dose for treating imDCs in subsequent assays. Western blotting results showed that expression of CTSK was inhibited by aspirin treatment, which was in accordance with RT-PCR results (Fig. 3c).

\section{Aspirin inhibited RANKL-induced OCs by directly} inhibiting the IKK/IKB/NF-Kb/NFATc1 pathway

$\mathrm{NF}-\mathrm{KB}$ is a dimeric transcription factor complex that plays a critical role in osteoclastogenesis [16, 17]. NFATc1 expression, which has an integral role in $\mathrm{OC}$ differentiation, is dependent on RANKL-NF- $\mathrm{KB}$ pathways. Additionally, previous studies have shown that aspirin can suppress the

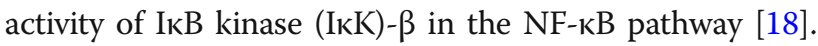
Thus, we detected the activities of NF- $\mathrm{kB}$-related proteins. The results showed that IкK, p-ІкK, І $\mathrm{B}$, and $\mathrm{p}$-ІкB expression increased after RANKL treatment and that aspirin reduced this upregulation (Fig. 4a, c). In addition, RANKL promoted P65 and NFATc1 nuclear translocation, whereas aspirin treatment suppressed this effect (Fig. 4a, c). Subsequent experiments were carried out for verification purposes. To this end, we blocked the IкK/ ІкB/NF-кB pathway with the ІкK- $\beta$ inhibitor (IMD 0354; Selleck, USA) before RANKL treatment and found that the RANKL-induced upregulation of IкB and p-IкB protein expression was suppressed. In addition, the IкK- $\beta$ inhibitor blocked NFATc1 nuclear translocation (Fig. 4b).

Importantly, these results indicated that the NF-Kb/ NFATc1 pathway is involved in aspirin-mediated inhibition of the differentiation of DCs into OCs (Fig. 4d).

\section{Aspirin treatment showed favorable therapeutic effects on bone regeneration}

To identify the abilities of aspirin-pretreated DDOCs in a bone defect, we generated a defect $(5 \mathrm{~mm} \times 2 \mathrm{~mm} \times 1$ $\mathrm{mm}$ ) in the rat mandible (Fig. 5a). Defect healing in the aspirin group occurred more rapidly than in the control group at 2 weeks (Fig. 5b; $P<0.05$ ). Two months later, the aspirin group showed a favorable defect-to-healing ratio (Fig. $5 \mathrm{c} ; P<0.01$ ). In addition, H\&E staining of bone defect sections acquired from both groups showed
$\begin{array}{llllllll}A & \min & 0 & 15 & 30 & 60 & \text { B }\end{array}$

IKK 1

p-IKK $\because \cdots+1=$

p-p65 $-=-=$

IKB

p-IKB

H90

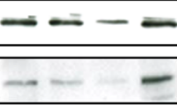

RANKL

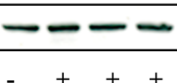

D

Aspirin/Inhibitor pretreated in DCs

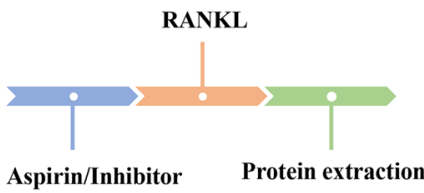

B

\section{IKB} p-IKB

H90

NFATc1

H3

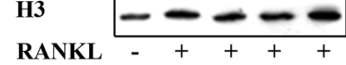

IKK inhibitor $\quad-\quad-\quad 0.5 \quad 1.05 .0$

$(\mu \mathrm{m})$

E

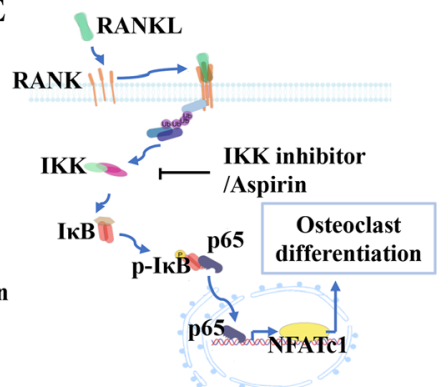

C

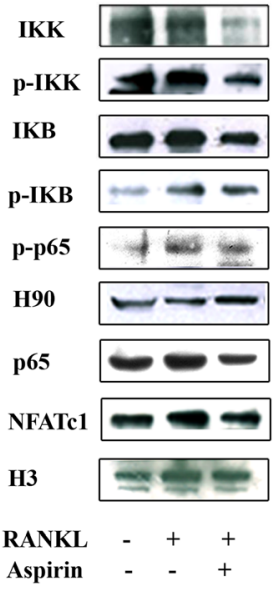

Fig. 4 Aspirin inhibits RANKL-induced OCs via the $1 \mathrm{KK} / \mathrm{IKB} / \mathrm{NF}-\mathrm{KB}$ pathway. $\mathbf{a}$, b Western blot showing that RANKL treatment upregulated IKK, $\mathrm{p}$ IKK, IKB, p-IKB, and p-p65 and that IKK inhibitor treatment significantly reduced this upregulation. The expression levels of NFATc1 showed the same tendency. c Components of the IKK/IKB/NF-KB pathway were overexpressed after RANKL induction, which was decreased by aspirin pretreatment, with the results for NFATC1 expression being consistent. $\mathbf{d}$ Schematic representation of the timing of aspirin and IKK inhibitor treatment in our experiments. e Based on all of the results described above, aspirin inhibits RANKL-induced OCs via the NF-KB pathway, ultimately suppressing NFATc1 synthesis. All experiments are representative of at least three replicates 


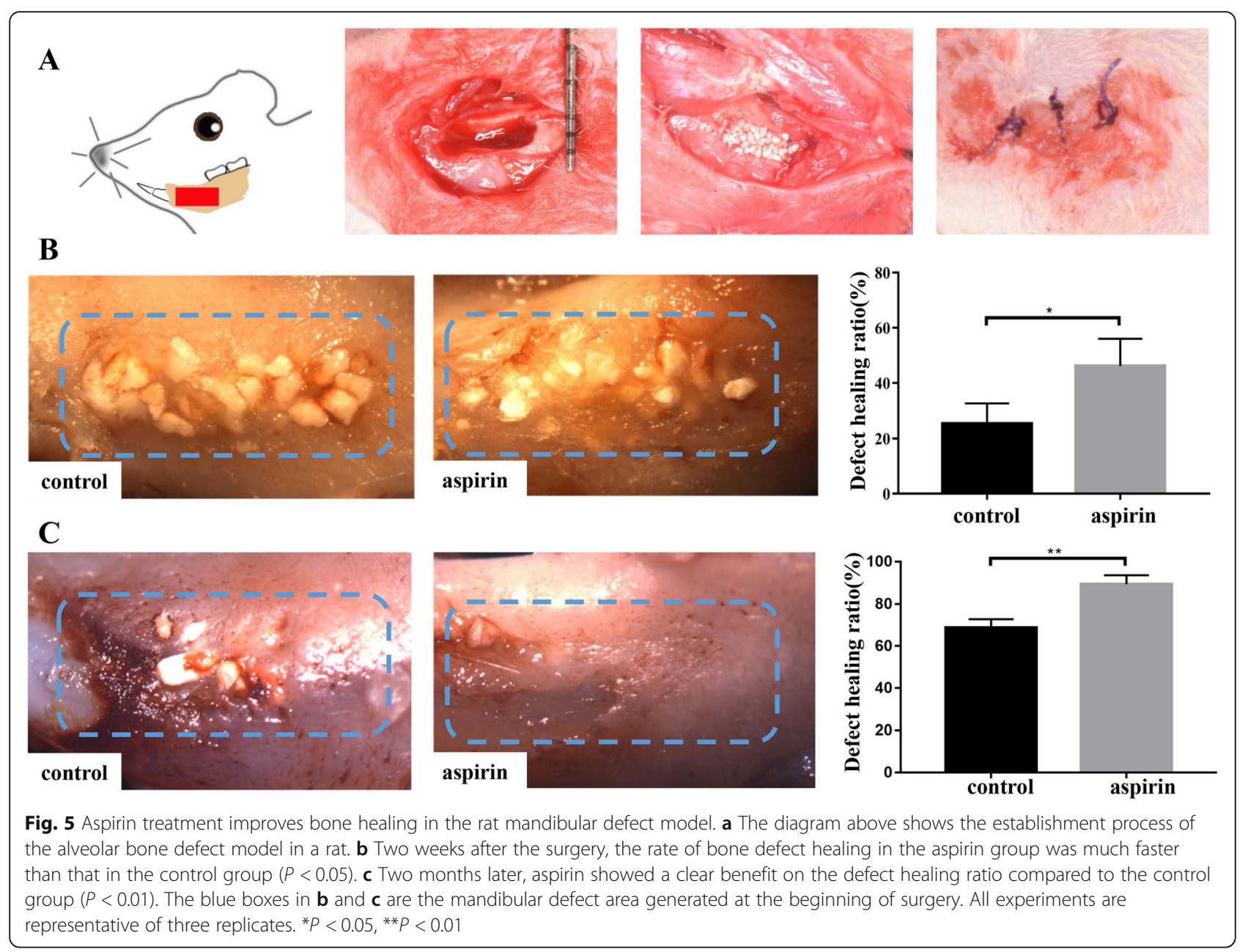

that aspirin promoted bone healing (Fig. 6g; $\mathrm{P}<0.05$ ). In the control group, new bone had formed over the bone defect surface with a moderate number of new blood vessels (Fig. $6 \mathrm{a}-\mathrm{c}$ ). HA/TCP particles were found in the mineralized tissue. However, numerous new bones were observed in the aspirin group, which exhibited almost complete repair of the bone defect, and new bone formation was still active around the surface of the HA/ TCP particles (Fig. 6d-f).

\section{Aspirin inhibited $O C$ differentiation in the bone defect model}

The number of local OCs was examined in the bone defect model. According to TRAP staining, OCs remained around the bone defect in both groups showed on the third day (Fig. 7a-d). Additionally, the aspirin group exhibited a significant reduction in the number of OCs (Fig. 7i; $P<0.05$ ). Most studies have indicated that immature $\mathrm{CD}_{11 \mathrm{c}^{+}} \mathrm{DCs}$ can act as $\mathrm{OC}$ precursors and thus become functional $\mathrm{OCs}$ in the inflammationinduced bone environment [19]. Thus, we adopted immunohistochemical staining to verify that the number of
CD11 $\mathrm{c}^{+}$cells increased in both groups (Fig. $7 \mathrm{e}-\mathrm{h}$ ) and found a lower number of $\mathrm{CD}_{11 \mathrm{c}^{+}}$cells in the aspirin group than in the control group (Fig. 7j; $P<0.05$ ).

\section{Discussion}

Under physiological conditions, bone mass maintenance is achieved through a delicate balance between bone formation by osteoblasts and bone resorption by OCs. However, in certain inflammatory diseases, this balance is disrupted, and the activation of OCs predominates, resulting in localized bone erosion. Thus, it is important to understand the mechanisms underlying the relative activity of OCs to minimize bone injury in these inflammatory diseases [2].

Osteoclastogenesis depends on progenitor cells of the monocyte hematopoietic lineage, and these progenitor cells have been demonstrated to fuse to form OCs under the influence of M-CSF and RANKL [2, 4]. In addition, human DCs can differentiate into mature OCs [20]. In agreement with this, several researchers have generated OCs from splenic or bone marrow-derived mouse DCs in a RANKL-dependent manner [21]. Moreover, DCs are considered to be more efficient at differentiating into OCs 

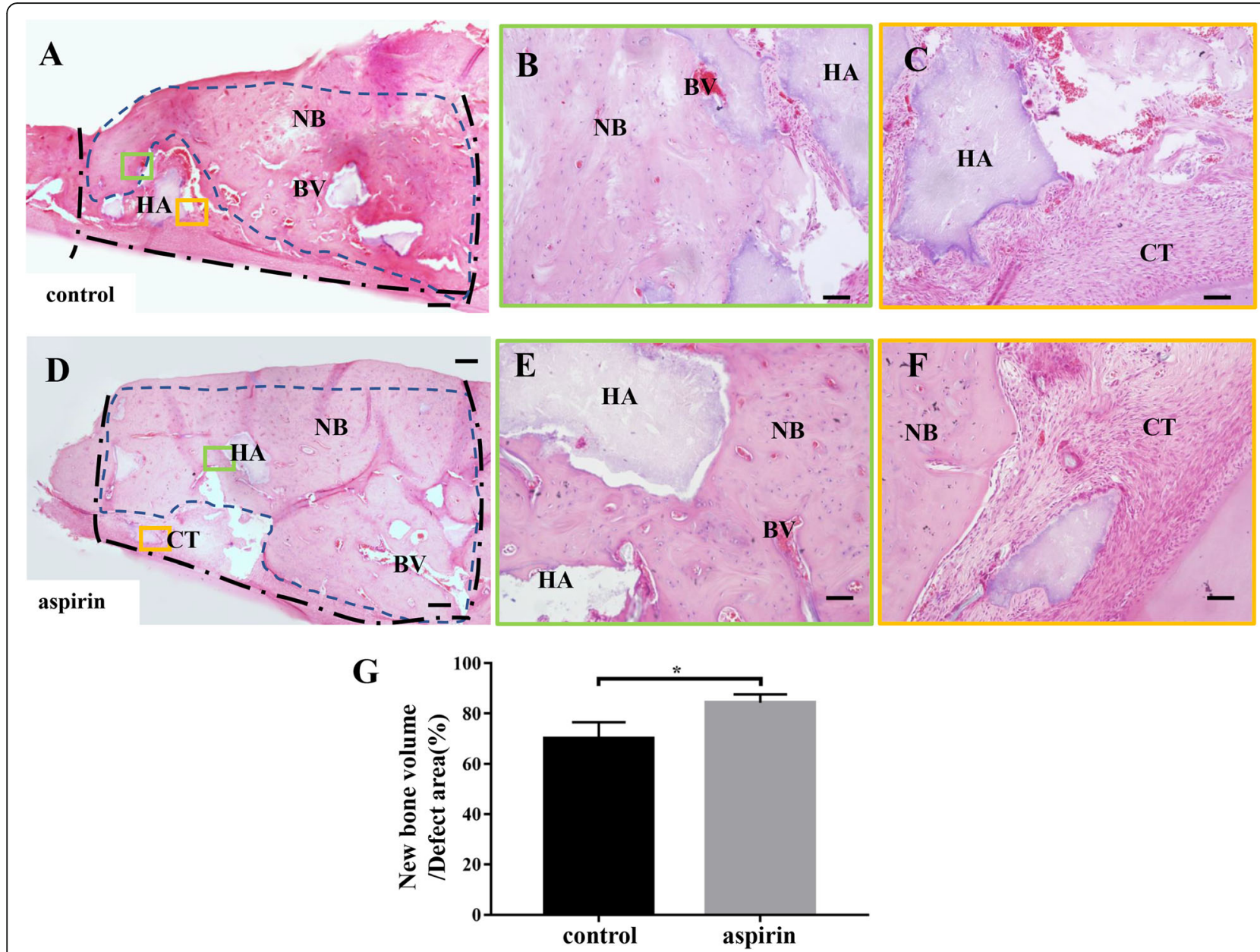

Fig. 6 Aspirin treatment promotes HA/TCP-mediated new bone formation in the rat mandibular defect model. a Two months after surgery, new bone and blood vessels were observed in the control group. HATCP was also detected in the mineralized tissues. (Black lines show the margins of the bone defect generated during surgery. Blue lines show the area of new bone formation.) $\mathbf{b}$ The area of a green rectangle in $\mathbf{a}$ shows new bone around HA/TCP particles under a high-magnification microscope, and new blood vessels can be seen between the bone. $\mathbf{c}$ Large volumes of connective tissues remain at the edge of the bone defect, which surround the HA/TCP particles. (The area enclosed with a yellow rectangle in a.) $\mathbf{d}$ New bone formation almost completely repaired the bone defect in the aspirin group after 2 months. (Black lines show the margins of the bone defect generated during surgery. Blue lines show the area of new bone formation.) e The area in a green rectangle of $\mathbf{d}$ shows new bone formation and a large number of new surrounding blood vessels. $\mathbf{f}$ Higher magnification of the area in a yellow rectangle in $\mathbf{d}$ shows osteoblasts surrounding the surface of HA/TCP particles, with new bone formation still being active. $\mathbf{g}$ Two months later, aspirin treatment accelerated bone regeneration compared to the control group $(P<0.05)$. HA $=$ HA/TCP particles, $C T=$ connective tissue, $B V=b l o o d$ vessel, NB= new bone. Scale bar $=200 \mu \mathrm{m}$ in $\mathbf{a}$, $\mathbf{d}$ and $\mathbf{s c a l e}$ bar $=50 \mu \mathrm{m}$ in $\mathbf{b}, \mathbf{c}, \mathbf{e}, \mathbf{f}$

than are monocytes in terms of fusion efficiency and the number of nuclei per OC, suggesting that DCs might have an unexpected direct role in osteoclastogenesis $[22,23]$. Accordingly, downregulation of DDOC differentiation or function may be an ideal target for the treatment of pathological bone diseases.

Aspirin is an NSAID commonly used in clinical applications because of its various antipyretic, analgesic, antirheumatic, and anti-platelet aggregation effects [19, 24]. The properties of aspirin involve a variety of pathways, such as inhibition of COX-2 and COX-1 and prostaglandin E2 (PGE2) activities [7, 25, 26]. PGE2 is a multifunctional regulator of bone metabolism that affects bone resorption and formation [27], and previous studies have shown that treatment with COX-2-specific NSAIDS reduce levels of PGE2 while negatively affecting bone healing [28]. The inhibitory effect of aspirin on bone healing has also been demonstrated in four animal studies and a human in vitro study [8, 29-32]. Nonetheless, a recent study indicated that aspirin has positive effects on cranial bone regeneration in miniature pigs, partly by promoting bone marrow mesenchymal stem cell-based osteogenesis [8]. Moreover, epidemiological studies have demonstrated that frequent use of aspirin may have a moderate beneficial effect on bone mineral density in postmenopausal women [33]. In general, the controversial results may depend on the preparations 


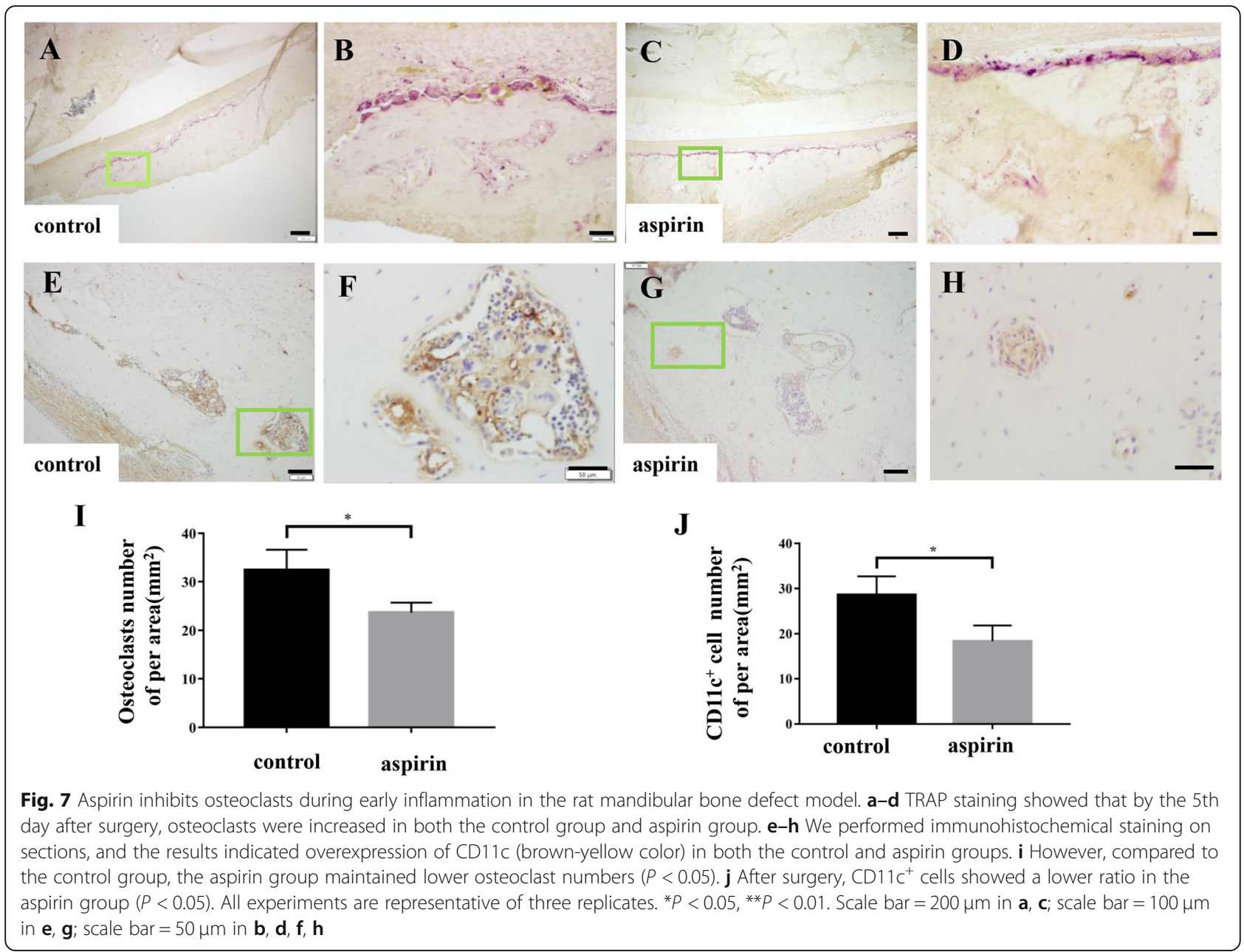

of the drug, modes of administration, doses, and ability to inhibit COX-2. Aspirin inhibits OCs [34] by promoting telomerase activity and also dramatically activates osteoblasts $[26,35]$. In addition, exogenous PGE2 may strongly stimulate bone resorption in bone organ cultures and osteoclast differentiation in bone marrow cultures. PGE2 has biphasic effects on RANKL-induced OC formation in bone marrow cultures [27]. For example, PGE2 increases RANKLinduced OC differentiation in RAW264.7 cells [36] but inhibits differentiation in cultured human peripheral blood mononuclear cells (PBMCs) [37]. Furthermore, aspirin was shown to inhibit RANKL-induced osteoclastogenesis in RAW264.7 cells [14] and to decrease bone resorption by downregulating PGE2 both in vivo and in vitro [38]. Regardless, the inhibitory potential and mechanisms of aspirin with regard to the differentiation of DCs into OCs have not been elucidated.

In this study, we observed that DCs were able to induce $\mathrm{TRAP}^{+} \mathrm{OC}$ formation in response to RANKL and that this process was inhibited by aspirin. We further investigated the underlying molecular mechanisms involving aspirin in $\mathrm{OC}$ differentiation and function. The
RANKL/RANK/osteoprotegerin (OPG) axis is the classic regulatory system of bone metabolism, and it can regulate OC differentiation $[39,40]$. Binding of RANKL to its receptor RANK results in rapid recruitment of multiple intracellular signaling molecules, such as MAPK, NF- $\mathrm{kB}$, AP-1, TRAFs, and NFATc1, with NF-kB being the most important factor [41]. Indeed, NF- $\mathrm{kB}$ signaling has been shown to play an essential role in osteoclastogenesis, and its suppression can inhibit NFATc1 expression [42]. Previous research demonstrated that the NF- $\mathrm{kB}$ inhibitor (-)-dehydroxymethylepoxyquinomicin suppresses RANKLinduced osteoclastogenesis by downregulating NFATc1 expression [43]. In the present study, we found that treatment with aspirin suppressed RANKL-induced NF- $\mathrm{kB}$ signaling pathways.

Multiple previous studies have established that during osteoclastogenesis, NFATc1 is the specific transcription factor that regulates OC-specific genes, such as cathepsin K, TRAP, and CTR, involved in the regulation of RANKL-mediated OC differentiation, fusion, and activation $[39,44]$. The present data suggest that stimulation of imDCs with RANKL leads to expression of NFATc1 
and that aspirin treatment reduces RANKL-induced NFATc1 activation. Collectively, these results indicate that aspirin effectively inhibits $O C$ differentiation in imDCs by regulating NF- $\mathrm{kB}$ induction and NFATc1 following RANKL/RANK interaction.

\section{Conclusion}

In summary, our results demonstrate that aspirin downregulates the RANKL-mediated induction of NF- $\mathrm{KB}$ and NFATc1. This effect then participates in downregulating expression of the downstream nuclear transcription factor NFATc1 and inhibiting RANKL-induced OC differentiation in preosteoclastic imDCs. However, further investigations into the role of imDCs in bone resorption and the feasibility of using aspirin in clinical applications are still required.

\footnotetext{
Abbreviations

a-MEM: a-minimum essential medium; BMSC: Bone marrow mesenchymal stem cell; CTR: Calcitonin receptor; CFSE: Carboxyfluorescein succinimidyl ester; CTSK: Cathepsin K; COX-1: Cyclooxygenase-1; COX-2: Cyclooxygenase-2; DCs: Dendritic cells; DDOCs: Dendritic cell-derived osteoclasts; H\&E: Hematoxylin and eosin; imDCs: Immature dendritic cells; MCSF: Macrophage colony-stimulating factor; MLR: Mixed lymphocyte reaction; mAbs: Monoclonal antibodies; NSAID: Nonsteroidal anti-inflammatory drug; NF-KB: Nuclear factor kappa B; NFATc1: Nuclear factor of activated T cell,cytoplasmic 1; OC: Osteoclast; OPG: Osteoprotegerin; PFA: Paraformaldehyde; PBMC: Peripheral blood mononuclear cell: PGE : Prostaglandin E2; RANKL: Receptor activator of nuclear factor-KB ligand; RT-PCR: Reverse transcription polymerase chain reaction; TRAP: Tartrateresistant acid phosphatase
}

\section{Acknowledgements}

This work was supported by grants from the National Nature Science Foundation of China (81470751 to Y. L, 81800968 to ZH. L, 81600891 to L.G), the Beijing Municipal Administration of Hospitals Clinical Medicine Development of Special Funding Support (ZYLX201703 to Y.B), the Beijing Baigianwan Talents Project (2017A17 to Y.L), Beijing Municipal Education Commission and Science Technology Project of the (KM201910025008 to ZH.L).

\section{Authors' contributions}

LW performed the research with the aid of YitL, $L$, and $Y J$ and drafted the manuscript. ZhL participated in the design of the study and helped draft the manuscript. JD participated in the statistical analysis. YB performed the experimental facility and coordination. LG helped to analyze the preliminary data. YiL conceived of the study and critically revised the manuscript. All authors read and approved the final manuscript.

\section{Funding}

This work was supported by grants from the National Nature Science Foundation of China 81470751 to Y. L (supporting the research), 81800968 to ZH. L (supporting experiments process), and 81600891 to L. G (supporting the manuscript preparation), the Beijing Municipal Administration of Hospitals Clinical Medicine Development of Special Funding Support (ZYLX201703 to Y. B, supporting data analysis), the Beijing Baiqianwan Talents Project (2017A17 to Y. L, supporting interpretation of data), Beijing Municipal Education Commission and Science Technology Project of the (KM201910025008 to ZH. L, supporting the design of the study).

\section{Availability of data and materials}

All data analyzed during the current study are included in this published article.

\section{Ethics approval and consent to participate}

We conducted the study following the informed guidelines approved by the Animal Ethical Committee of the School of Stomatology, Capital Medical
University (Beijing, China\#2012-x-53). All participants gave informed consent to participate in the study.

\section{Consent for publication}

Not applicable.

\section{Competing interests}

The authors declare that they have no competing interests.

\section{Author details}

'Laboratory of Tissue Regeneration and Immunology and Department of Periodontics, Beijing Key Laboratory of Tooth Regeneration and Function Reconstruction, School of Stomatology, Capital Medical University, Tian Tan Xi Li No.4, Beijing 100050, People's Republic of China. ${ }^{2}$ Department of Orthodontics, School of Stomatology, Capital Medical University, Beijing, China.

Received: 3 July 2019 Revised: 17 October 2019 Accepted: 20 November 2019 Published online: 05 December 2019

\section{References}

1. Boyle WJ, Simonet WS, Lacey DL. Osteoclast differentiation and activation. Nature. 2003;423(6937):337-42

2. Charles JF, Aliprantis AO Osteoclasts: more than 'bone eaters'. Trends Mol Med. 2014;20(8):449-59.

3. Miyamoto T, Ohneda O, Arai F, Iwamoto K, Okada S, Takagi K, et al. Bifurcation of osteoclasts and dendritic cells from common progenitors. Blood. 2001;98(8):2544-54

4. Lapérine O, Blin-Wakkach C, Guicheux J, Beck-Cormier S, Lesclous P. Dendritic-cell-derived osteoclasts: a new game changer in bone-resorptionassociated diseases. Drug Discov Today. 2016;21(9):1345-54

5. Speziani C, Rivollier A, Gallois A, Coury F, Mazzorana M, Azocar O, et al. Murine dendritic cell transdifferentiation into osteoclasts is differentially regulated by innate and adaptive cytokines. Eur J Immunol. 2007:37(3):747-57.

6. Tucci M, Stucci S, Savonarola A, Ciavarella S, Cafforio P, Dammacco F, et al. Immature dendritic cells in multiple myeloma are prone to osteoclast-like differentiation through interleukin-17A stimulation. Br J Haematol. 2013; 161(6):821-31.

7. Yamaza T, Miura Y, Bi Y, Liu Y, Akiyama K, Sonoyama W, et al. Pharmacologic stem cell based intervention as a new approach to osteoporosis treatment in rodents. PLoS One. 2008;3(7):e2615.

8. Allen HL, Wase A, Bear WT. Indomethacin and aspirin: effect of nonsteroidal anti-inflammatory agents on the rate of fracture repair in the rat. Acta Orthop Scand. 1980;51(4):595-600.

9. Goodman S, Ma T, Trindade M, Ikenoue T, Matsuura I, Wong N, et al. COX-2 selective NSAID decreases bone ingrowth in vivo. J Orthop Res. 2002:20(6):1164-9.

10. Trancik T, Mills W, Vinson N. The effect of indomethacin, aspirin, and ibuprofen on bone ingrowth into a porous-coated implant. Clin Orthop Relat Res. 1989;249:113-21

11. Mullis BH, Copland ST, Weinhold PS, Miclau T, Lester GE, Bos GD. Effect of COX-2 inhibitors and non-steroidal anti-inflammatory drugs on a mouse fracture model. Injury. 2006;37(9):827-37.

12. Brown KM, Saunders MM, Kirsch T, Donahue HJ, Reid JS. Effect of COX-2specific inhibition on fracture-healing in the rat femur. J Bone Joint Surg Am. 2004:86(1):116-23.

13. Long J, Lewis S, Kuklo T, Zhu Y, Riew KD. The effect of cyclooxygenase-2 inhibitors on spinal fusion. J Bone Joint Surg Am. 2002:84(10):1763-8.

14. Zeng YP, Yang C, Li Y, Fan Y, Yang HJ, Liu B, et al. Aspirin inhibits osteoclastogenesis by suppressing the activation of NF-KB and MAPKs in RANKL-induced RAW264.7 cells. Mol Med Rep. 2016;14(3):1957-62.

15. Cao Y, Xiong J, Mei S, Wang F, Zhao Z, Wang S, et al. Aspirin promotes bone marrow mesenchymal stem cell-based calvarial bone regeneration in mini swine. Stem Cell Res Ther. 2015;6:210

16. Shinohara M, Takayanagi H. Novel osteoclast signaling mechanisms. Curr Osteoporos Rep. 2007:5(2):67-72.

17. de la Rica L, García-Gómez A, Comet NR, Rodríguez-Ubreva J, Ciudad L, Vento-Tormo $R$, et al. NF-KB-direct activation of microRNAs with repressive effects on monocyte-specific genes is critical for osteoclast differentiation. Genome Biol. 2015;16:2. 
18. Yin MJ, Yamamoto Y, Gaynor RB. The anti-inflammatory agents aspirin and salicylate inhibit the activity of I (kappa) B kinase-beta. Nature. 1998; 396(6706):77-80.

19. Kristensen DM, Mazaud-Guittot S, Gaudriault P, Lesné L, Serrano T, Main KM et al. Analgesic use - prevalence, biomonitoring and endocrine and reproductive effects. Nat Rev Endocrinol. 2016;12(7):381-93.

20. Rivollier A, Mazzorana M, Tebib J, Piperno M, Aitsiselmi T, Rabourdin-Combe C, et al. Immature dendritic cell transdifferentiation into osteoclasts: a novel pathway sustained by the rheumatoid arthritis microenvironment. Blood. 2004;104(13):4029-37.

21. Alnaeeli M, Penninger JM, Teng YT. Immune interactions with $\mathrm{CD}^{+}{ }^{+} \mathrm{T}$ cells promote the development of functional osteoclasts from murine $\mathrm{CD}_{11 \mathrm{C}^{+}}$ dendritic cells. J Immunol. 2006;177(5):3314-26.

22. Alnaeeli M, Park J, Mahamed D, Penninger JM, Teng YT. Dendritic cells at the osteo-immune interface: implications for inflammation-induced bone loss. J Bone Miner Res. 2007;22(6):775-80.

23. Gallois A, Lachuer J, Yvert G, Wierinckx A, Brunet F, Rabourdin-Combe C, et al. Genome-wide expression analyses establish dendritic cells as a new osteoclast precursor able to generate bone-resorbing cells more efficiently than monocytes. J Bone Miner Res. 2010;25(3):661-72.

24. Bauer DC, Orwoll ES, Fox KM, Vogt TM, Lane NE, Hochberg MC, et al. Aspirin and NSAID use in older women: effect on bone mineral density and fracture risk. Study of osteoporotic fractures research group. J Bone Miner Res. 1996;11(1):29-35.

25. Lack WD, Fredericks D, Petersen E, Donovan M, George M, Nepola J, et al. Effect of aspirin on bone healing in a rabbit ulnar osteotomy model. J Bone Joint Surg Am. 2013;95(6):488-96.

26. Shi S, Yamaza T, Akiyama K. Is aspirin treatment an appropriate intervention to osteoporosis? Fut Rheumatol. 2008;3(6):499-502.

27. Blackwell KA, Raisz LG, Pilbeam CC. Prostaglandins in bone: bad cop, good cop? Trends Endocrinol Metab. 2010;21(5):294-301.

28. Simon AM, O'Connor JP. Dose and time-dependent effects of cyclooxygenase-2 inhibition on fracture-healing. J Bone Joint Surg Am. 2007;89(3):500-11.

29. Baratieri A, Deli R. The effect on bone repair of aspirin cones placed in extraction sockets in dogs: a histopathologic study. J Oral Pathol. 1979;8(4): 198-206.

30. Carroll PB, Melfi RC. The histologic effect of topically applied acetylsalicylic acid on bone healing in rats. Oral Surg Oral Med Oral Pathol. 1972;33(5):728-835.

31. Mizuno H, Liang RF, Kawabata A. Effects of oral administration of various non-steroidal anti-inflammatory drugs on bone growth and bone wound healing in mice. Meikai Daigaku Shigaku Zasshi. 1990;19(2):234-50.

32. Guida L, Annunziata M, Passaro I, Buonaiuto C, Rullo R, Tetè S, et al. Acetylsalicylic acid inhibits proliferation of human bone marrow stromal cells and matrix mineralization. Int J Immunopathol Pharmacol. 2008;21(4):921-8.

33. Carbone LD, Tylavsky FA, Cauley JA, Harris TB, Lang TF, Bauer DC, et al. Association between bone mineral density and the use of nonsteroidal antiinflammatory drugs and aspirin: impact of cyclooxygenase selectivity. J Bone Miner Res. 2003;18(10):1795-802.

34. Lussana F, Squizzato A, Permunian ET, Cattaneo M, et al. A systematic review on the effect of aspirin in the prevention of post-operative arterial thrombosis in patients undergoing total hip and total knee arthroplasty. Thromb Res. 2014;134(3):599-603.

35. Chen C, Akiyama K, Yamaza T, You YO, Xu X, Li B, et al. Telomerase governs immunomodulatory properties of mesenchymal stem cells by regulating FAS ligand expression. EMBO Mol Med. 2014;6(3):322-34.

36. Kobayashi Y, Mizoguchi T, Take I, Kurihara S, Udagawa N, Takahashi N. Prostaglandin E2 enhances osteoclastic differentiation of precursor cells through protein kinase A-dependent phosphorylation of TAK1. J Biol Chem. 2005;280(12):11395-113403.

37. Take I, Kobayashi Y, Yamamoto Y, Tsuboi H, Ochi T, Uematsu S, et al. Prostaglandin E2 strongly inhibits human osteoclast formation. Endocrinology. 2005;146(12):5204-14.

38. Norrdin RW, Jee WS, High WB. The role of prostaglandins in bone in vivo. Prostaglandins Leukot Essent Fatty Acids. 1990;41(3):139-49.

39. Ahern E, Smyth MJ, Dougall WC, Teng MWL. Roles of the RANKL-RANK axis in antitumour immunity - implications for therapy. Nat Rev Clin Oncol. 2018; 15(11):676-93.

40. Xiong J, Cawley K, Piemontese M, Fujiwara Y, Zhao H, Goellner JJ, et al. Soluble RANKL contributes to osteoclast formation in adult mice but not ovariectomy-induced bone loss. Nat Commun. 2018;9(1):2909.
41. Tan EM, Li L, Indran IR, Chew N, Yong EL, et al. TRAF6 mediates suppression of osteoclastogenesis and prevention of ovariectomy-induced bone loss by a novel prenylflavonoid. J Bone Miner Res. 2017;32(4):846-60.

42. Zhang Y, Xu S, Li K, Tan K, Liang K, Wang J, et al. mTORC1 inhibits NF-KB/ NFATC1 signaling and prevents osteoclast precursor differentiation, in vitro and in mice. J Bone Miner Res. 2017;32(9):1829-40.

43. Takatsuna H, Asagiri M, Kubota T, Oka K, Osada T, Sugiyama C, et al. Inhibition of RANKL-induced osteoclastogenesis by (-)-DHMEQ, a novel NFKB inhibitor, through downregulation of NFATc1. J Bone Miner Res. 2005; 20(4):653-62.

44. Lorenzo J. The many ways of osteoclast activation. J Clin Invest. 2017; 127(7):2530-2.

\section{Publisher's Note}

Springer Nature remains neutral with regard to jurisdictional claims in published maps and institutional affiliations.

\section{Ready to submit your research? Choose BMC and benefit from:}

- fast, convenient online submission

- thorough peer review by experienced researchers in your field

- rapid publication on acceptance

- support for research data, including large and complex data types

- gold Open Access which fosters wider collaboration and increased citations

- maximum visibility for your research: over $100 \mathrm{M}$ website views per year

At BMC, research is always in progress.

Learn more biomedcentral.com/submissions 